\title{
Rural-Urban Disconnect: Outmigration of Elderly Persons' Offspring and Social Exclusion of the Elderly
}

\author{
Austine Ochieng Dieto ${ }^{1 *}$, Kibet A. Ngetich ${ }^{2}$, Wafula Kisaka ${ }^{1}$
}

${ }^{1}$ Department of Peace Security and Social Studies; Egerton University, PO BOX 536 Njoro, Kenya

${ }^{2}$ Professor, Department of Peace Security and Social Studies; Egerton University, PO BOX 536 Njoro, Kenya

DOI: $10.36347 /$ sjahss.2020.v08i11.002

| Received: 09.11.2020 | Accepted: 21.11.2020 | Published: 25.11.2020

*Corresponding author: Austine Ochieng Dieto

\section{Abstract}

Original Research Article

Rural-urban migration is the movement of people from countryside to cities or towns. Such migrations are likely to cause rural-urban disconnect which is characterized by the weakening of social ties between urban migrants and the elderly in the countryside. This study intended to establish the extent to which rural-urban migration of the elderly persons' offspring influenced social exclusion of the elderly in Alego-Usonga. The study established that migration of elderly persons' offspring had an influence on the livelihood of the elderly persons left behind by their migrant offspring. The study found that migration was largely motivated by the search for employment opportunities in urban centres. This was due to limited employment opportunities in Alego-Usonga which is largely rural and by extension, having limited opportunities to absorb the unemployed youth. This coupled with rural hardship and the negative perception of the younger migrant population towards rural life contributed to out-migration and disconnect. Limited physical contact between migrant offspring and the elderly persons left behind was defined by the limited rural visits by the migrant offspring as well as the minimal elderly persons' visit to the migration destinations to interact with their migrant offspring. Lastly the study established that majority of elderly persons felt socially excluded as a result of migration of their offspring to urban areas. Therefore, the findings confirm that indeed migration of elderly persons' offspring to urban areas influenced social exclusion of the elderly in Alego-Usonga and by extension contributed to the rural-urban disconnect.

Keywords: Social exclusion, elderly persons, offspring, rural-urban migration, rural-urban disconnect.

Copyright $\odot 2020$ The Author(s): This is an open-access article distributed under the terms of the Creative Commons Attribution 4.0 International License (CC BY-NC 4.0) which permits unrestricted use, distribution, and reproduction in any medium for non-commercial use provided the original author and source are credited.

\section{INTRODUCTION}

Modernity and urbanization have prompted the mass movement of youthful populations to urban areas to seek employment, investment and other personal development opportunities, leaving behind other members of the rural population like elderly persons with relatively less aptitude to take up vibrant economic activities in the urban areas [1]. This rural-urban drift has led to substantial loss of active youths from the rural areas thereby affecting economic output including food production in such outmigration areas [2, 3]. Similarly, Fapohonda [4] viewed mass movement of individuals from the rural areas to towns in Nigeria as not only bringing about rural depopulation but also loss of economic vibrancy. Fapohonda [4] further noted that migrants were in most cases the most productive members hence their migration was an impediment to the rural potential.
Luo Nyanza region in Kenya has been identified as one of the leading outmigration regions in Kenya [5]. Oucho and Mukras [5] observed that luos were more likely to migrate to urban centres in pursuit of wage employment as compared to other communities like Kikuyus who were inclined towards AgroEconomics. However, Oucho et al., [6] contend that the impact of such migration can be either positive or negative. The authors viewed migration as part of the solution to poverty in the rural areas as it presented the opportunity to migrant members that would enable such migrants increase their capacity to offer the necessary assistance to those left at home. On the other hand, the authors noted that departure of family members to towns reduced output in the rural areas since those left behind missed out on the skills that would have otherwise been provided by the migrant members. 
Cohen and Odhiambo [7] in an earlier study noted that migration was inevitable due to the limited opportunities available to the working population in the rural areas. The authors however observed that return visits by migrants to rural areas was critical in bridging the gap between the returning migrant and the rural community. Cohen and Odhiambo [7] reckoned that social ties between urban migrants were hardly affected due to the strong cultural pressure on the urban migrants to make timely return visits to their rural homes. For instance, pressure was placed on urban migrants to return to their rural homes especially during vacations to perform certain activities of cultural significance such as home establishment, attending burials and giving birth. Cohen and Odhiambo [7] noted that even though the period could be short, it was quite important in the 'resocialisation' of the returning urban migrant within that period of vacation. However, Cohen and Odhiambo [7] did not critically consider the possible adverse influence of modernity and urbanization on the social ties between migrant offspring and the elderly persons left behind. In addition, cultural pressure that used to be placed on urban migrants to return home has immensely reduced immensely in recent times due to the weakening of the family and community support structures. For instance, the tradition of giving birth in the rural home and burying the placenta somewhere within the homestead was outdated as giving birth at home in modern times is seen as a reproductive health concern. Therefore the current study came in handy by examining the influence of outmigration on elderly persons' social exclusion within the context of modernization and urbanization.

In conclusion, previous studies corroborate the influence of youth migration to urban areas on the rural economy. The studies also justify the relevance of outmigration of youths from Siaya County in the current study as a possible factor in older person's social exclusion. However, the focus on the influence of outmigration on rural development is only at macro level. There is little endeavor to examine the direct impact of such outmigration on elderly persons' social exclusion at individual level. There is further absence of literature on elderly persons' perception and that of the migrants with regard to the concept of outmigration and rural-urban disconnect. Therefore, this provided a strong justification for the current study which sought to examine social exclusion of elderly persons in relation to migration of their youthful offspring to urban areas.

This study was guided by the following objectives:

- To gauge the influence of outmigration of elderly persons' offspring on their social exclusion.

- To evaluate the perception of elderly persons on their level of social exclusion

- To assess the migrants' perception on their rural-urban disconnect

\section{RESEARCH METHODOLOGY}

The study mainly adopted a cross sectional survey design. This technique according to Nyandemo [8] is appropriate for examination of the qualities of the study subjects as they exist at one point in time and existing contrasts between study subjects rather than exploring change of attributes over a period of time. The main data collection tool was an interview schedule. Data was mainly analyzed through descriptive statistics to establish the coverage and access to various institutional social protection services for the elderly. A sample of 100 elderly persons was drawn through a two-staged cluster sampling technique.

To complement and to corroborate the quantitative data collected through cross sectional survey, the study also deployed a qualitative design through an in-depth interview of purposively selected key informants, namely, the Director of Social services in the County Government of Siaya and the Chairperson of Siaya Elderly Persons' welfare Association. In addition, a Focused group discussion was held virtually to gauge the migrant's perception on rural urban disconnect.

\section{FINDINGS AND DISCUSSION}

\section{Outmigration of elderly persons' offspring and social exclusion}

The study sought to establish the extent to which rural-urban migration of elderly persons' offspring influenced social exclusion of the elderly in Alego. In the current study, outmigration of elderly persons' offspring was reported by $71 \%$ of elderly persons with $19 \%$ representing cases where there was migration of all offspring to urban areas and a further $20 \%$ representing elderly persons with no living offspring. There was limited social contact between elderly persons and their migrant offspring as a result of greater spatial distance created through outmigration thereby perpetuating elderly persons' physical exclusion. The results of this study augment the findings of previous studies $[10,11]$ that noted that elderly persons were among the groups likely to be affected by migration patterns. However, the authors were particularly concerned with understanding how spatial distance affected social interaction between the migrants and the rural community at large without focus on elderly persons' social exclusion.

The study also went further to interrogate both the pull and push factors influencing outmigration. The findings reveal that rural-urban migration of elderly persons' offspring was mainly driven by the search for employment opportunities, business opportunities and education. Employment was the leading cause of outmigration as reported by majority of the elderly. Whereas the study showed limited social contact between elderly persons and their migrant offspring, the affected elderly persons concurred that their offspring's migration to urban areas was inevitable as the migrants 
had to migrate to look for employment opportunities to develop themselves. The elderly persons reckoned that without migration, their offspring would have no sustainable basis of livelihood due to the limited opportunities in the rural areas. The results confirm findings of previous studies [1, 2, 12] on youth outmigration from rural areas. However, these studies focused more on the impact of outmigration to the rural economy in general with limited focus on the influence on elderly persons and thereby providing the basis for the current study.

To further corroborate the influence of outmigration of elderly persons' offspring on elderly persons' social exclusion, the current study also looked at the frequency of rural visits by migrant offspring. The findings showed less frequent or no visits by migrant family members which further demonstrate the extent of physical exclusion. This finding is contrary to the observations by Cohen and Odhiambo [7] who in an earlier study in Siaya, indicated that cultural pressure tended to compel migrant members to make more frequent return visits which then provided a reliable basis of maintaining social ties between migrant members and those left at home. The findings of the current study on the other hand suggest little influence of cultural ties on offspring return visits thereby reiterating elderly persons' social exclusion. This is further corroborated by limited elderly persons' visit of their migrant offspring with the resultant effect being limited contact between migrant offspring and the elderly persons.

\section{Perception of elderly persons on their level of social exclusion}

The study examined elderly persons' perception on their social exclusion based on the extent of their interaction with their migrant offspring. Elderly persons felt socially excluded as a result of limited social contact with their migrant offspring. The respondents reported loneliness and limited visits by their migrant offspring, aggravated by limited communication. These observations thus confirmed the influence of outmigration on elderly persons' social exclusion. The findings therefore confirmed that indeed migration of elderly persons' offspring to urban areas influenced social exclusion of the elderly in AlegoUsonga Constituency, Siaya County due to the negative impact on both male and female elderly persons. This vindicates the specific objective of the current study which sought to establish the extent to which ruralurban migration of elderly persons' offspring influenced social exclusion of the elderly in Alego-Usonga. These finding augments recent findings by Estruch et al., [13] that affirmed weak rural-urban linkages caused by outmigration of youth.

\section{Migrants' perception on their rural-urban disconnect}

The study further looked into the various factors that contributed to the migrant-rural disconnect by assessing the migrant's perspective. The migrants outlined several factors that contributed to their rural disconnect. These included, bad blood between migrants and the rural folks; financial constraints; unrealistic societal expectations given the perceived success of the migrant; negative childhood experiences and repugnant cultural practices.

Firstly, the respondents cited unrealistic expectations by the rural folks whom they felt overburdened them by anticipating material support when they travel upcountry. The social interactions among rural communities are largely based on cohesive systems of kinship which is characterized by principles of interdependence among members of the community. However, when dependence tends to skewed to the disadvantage of the urban migrant, this is likely to discourage the migrant from making meaningful rural connections.

Migrants also attribute their rural disconnect to bad childhood memories and suffering in the hands of their relatives. Society provided mechanisms of taking care of orphans and vulnerable children by assigning a guardian, in most cases a close relative of the deceased parent. In some cases such orphans experience mistreatment from their guidance. When such children grow up and finally migrate to urban centres they tend to lack the motivation to return to that environment that reminds them of their painful childhood memories.

Further, financial constraints may hinder one's ability to travel to the countryside taking into consideration the societal expectation that the urban migrants who are perceived to be successful must provide handouts. Yet the migrants may not perceive themselves as successful. In some other cases, perceived failure by the urban migrants in terms of achieving social and economic aspirations may make them reluctant to return to the village. These perceived failures, according to migrants, include: unemployment, dropping out of school, unplanned pregnancy, business failure and marital problems.

Lastly, there is a perceived role of harmful practices believed to have been prevalent in certain rural areas. Some respondents cite factors such as witchcraft as factors discouraging them from making meaningful connections with their rural counterparts. Such findings are in concurrence with Oucho et al., [6] who reported that harmful cultural practices were among the drivers of outmigration in Siaya County. 


\section{CONCLUSION}

Firstly, this study has established that migration of elderly persons' offspring to urban areas actually had an influence on social exclusion of the elderly in Alego-Usonga Constituency Siaya County as a result of the negative influence it had on the livelihood of elderly persons. The findings confirmed existence of greater spatial distance between elderly persons and the migrant offspring which pointed to physical exclusion. In addition, elderly persons' physical exclusion was contributed by limited return visits by migrant offspring and further corroborated by elderly persons' own perception on the influence of their offspring outmigration on their social exclusion. Lastly, migrants cited challenges such as financial constraints; overdependence by rural folks; unrealistic societal expectations; bad childhood memories; their perceived failures and harmful cultural practices prevalent in some rural settings.

\section{RECOMMENDATIONS}

This study established that majority of elderly persons in Alego-Usonga experienced social exclusion as a result of limited social contact with their migrant offspring. There is need for development stakeholders in Alego-Usonga to promote strong rural-urban linkages by providing incentives for young urban migrants to equally invest their time and resources back home thereby redressing intergenerational gap between elderly persons and their migrant offspring. There is need to develop policies and programs aimed at creating employment opportunities in rural areas to control outmigration. Lastly, there is need for community-based organizations to spearhead behavior change strategies that can remove socio-cultural hindrances in order to promote better rural-urban linkages.

\section{REFERENCES}

1. Abbott D, Pollard S. Hardship and Poverty in the Pacific: Asian Development Bank Report. Asian Development Bank, Manila, 2004.

2. Adesiji B, Omoniwa V, Adebayo S, Matanmi B, Akangbe J. Factors Associated With The Youths' Rural-Urban Drift In Kwara State, Nigeria, Interdisciplinary Journal of contemporary Research in Business. 2009; 1(8):69-77.
3. Mwanzia P. The Effect of Older person's Cash Transfer Programme on the elderly in Westlands Sub-County, Nairobi City County. University of Nairobi, Nairobi, 2015:4-6.

4. Fapohunda, J. Economic consequences of ruralurban migration in Nigeria. In Odunmosu $\mathrm{O}$, Aluko SA, Adepoju A. Proceeding of the 3rd National Seminal Workshop on Problems of Migration in Nigeria, University of Ife, Caxton Press (W/A) Ltd, 2002.

5. Oucho J, Mukras S. Migration, Transfers and Rural Development: A Case Study of Kenya. International Development Research Centre (IDRC) Report, Ottawa, 1983.

6. Oucho J, Oucho L, Ochieng' V. Is Migration the Solution to Poverty Alleviation in Kenya? RuralUrban Migration Experiences of Migrants from Western Kenya to Kisumu and Nairobi: Migrating out of Poverty Research Programme Consortium Report, 2014

7. Cohen W, Odhiambo AS. The Historical Anthropology of an African Landscape. Ohio University Press, Athens, 1989.

8. Nyandemo S. Research Methodology. Richmond Printers, Nairobi, 2012.

9. Arudo T. Out migrants from Siaya District, Kenya: Volumes and Destinations, Post Graduate Diploma Project, University of Nairobi, Nairobi, 1988:7678

10. Bobrova A, Shakhotska L, Shymanovich G. Social Impact of Emigration and Rural-Urban Migration in Central and Eastern Europe. Final Country Report Belarus: European Commission, 2012.

11. History, Characteristics and Consequences of Rural-Urban Migration and Urbanization in Kenya. Available fromhttps://www.researchgate.net/publication/301 229237_History_Characteristics_and_Consequenc es_of_RuralUrban_Migration_and_Urbanization_I n_Kenya/citation/download

12. Scoping study on defining and measuring distress migration. Available from http://www.gsdrc.org/wpcontent/uploads/2017/04/HDR1406.pdf

13. Dynamic rural-urban linkages for decent rural employment. Available from http://www.fao.org/3/a-i6595e.pdf 